\title{
Satisfactory throat-hit is needed to switch from tobacco to e-cigarettes: a lesson from an e-liquid blind test
}

\author{
Bertrand Dautzenberg ${ }^{1,2,3}$, Alexandre Scheck ${ }^{4}$, Daniel Garelik ${ }^{1}$, Celine Kayal ${ }^{2,4,5}$, Marie \\ Dominique Dautzenberg ${ }^{3}$
}

\begin{abstract}
BACKGROUND The aim of the study was to confirm or reject the hypothesis that variation in throat-hit depends on the nicotine concentration and the voltage applied to the resistance. A secondary aim was to assess the influence of throat-hit on the willingness of subjects to switch from tobacco to e-cigarette use."

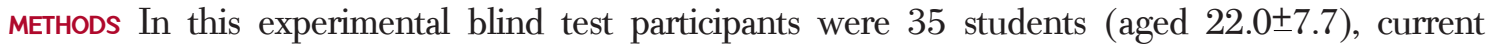
smokers, who tested five e-liquids with a nicotine concentration between 0 to $18 \mathrm{mg} / \mathrm{mL}$, at 3.5 or 4.5

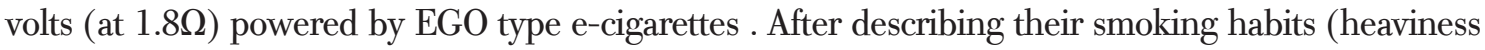
smoking index (HSI), and signing consent, participants smoked 1 puff every 5 minutes, inhaling for 3 seconds, for each of the 10 conditions and rated their subjective experience.

RESULTS Analysis of the 350 puffs from the 35 smokers,indicated a learning process of 5 puffs. Within this population a nicotine concentration of $12.6 \mathrm{mg} / \mathrm{mL}$ combined to 3.5volts and $10.9 \mathrm{mg} /$ $\mathrm{mL}$ combined to 4.5 volts was associated with OTH. Our results indicated a link between tobacco dependence and nicotine concentration of the e-liquid that provided an optimal throat-hit (OTH), with an $+1.6 \mathrm{mg} / \mathrm{mL}$ increase in nicotine content needed for the OTH for each one point increase in HSI. A link between the desire to switch from tobacco to e-cigarettes and the score of throat-hit was identified ( $r 2=0.94$ ). This desire is $<1 / 10$ when throat-hit is unpleasant (score $0-3$ ) and exceeds $7 / 10$ when throat-hit is optimal (score 7-10).

conclusions The present data justifies the need to further develop e-cigarettes so that an optimal OTH is identified quickly. Further research is needed to confirm the above results in other populations and to assess the specific influence of flavour on throat hit.
\end{abstract}

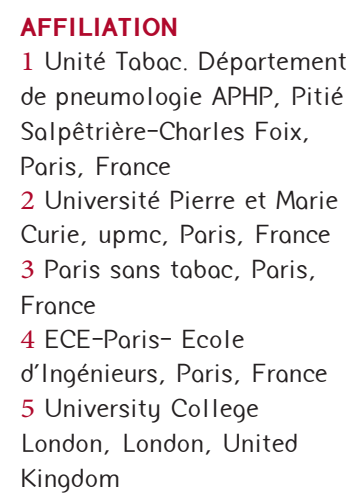

CORRESPONDENCE TO Pr Bertrand Dautzenberg Pneumology HU PitiéSalpêtrière 85 Bd Hôpital 75651 Paris Cedex 13,

France

bdautz@gmail.com

\section{KEY WORDS}

e-cigarette, e-liquid, throat-hit, blind test

\section{INTRODUCTION}

Throat-hit is the sensation felt in the throat during the first 6 seconds after taking a cigarette puff. This effect occurs before nicotine reaches the brain and is initiated by local nerve stimulation and not by brain nicotine receptors. The sensory branches of the trigeminal nerves are responsible for this effect ${ }^{1}$. The tobacco industry is aware that an unpleasant sensation in the mouth and throat is an obstacle to cigarette consumption and hence they try to avoid a too unpleasant throat-hit. They also know that nicotine addiction drives the daily smoker's consumption $^{2}$. When a regular smoker is asked to evaluate the throat-hit of the cigarette brand regularly used, the given throathit score is better than for another cigarette brand ${ }^{3}$ and partially explains the reason why a smoker, in most cases, uses only one brand for years and is unhappy to change as other cigarettes may be either too strong, too light or unpleasant in the throat.

An optimal sensorial effect of throat-hit is also a determinant of success of switching to an e-cigarette from tobacco use $\mathrm{e}^{4-6}$. This optimal throat-hit $(\mathrm{OTH})$ needs a high concentration of nicotine in e-liquid for recent former smokers, while after some months without any tobacco use, a "softer" e-liquid with a lower level of nicotine is optimal ${ }^{7}$. As for tobacco users, the absence of an unpleasant effect in the mouth and throat plays also a role in compliance to oral Nicotine Replacement Therapy (NRT) therapy ${ }^{8-10}$.

Our initial hypothesis, coming from clinical experience, is that the nicotine concentration in e-liquid needed to obtain an optimal throat-hit and increase the desire to switch from tobacco to e- 
cigarettes may vary from one smoker to another. The electric power applied to the e-cigarette resistance modulates this response and is explored in this pilot study. The flavours and other additives in the e-liquid could potentially also play a role, but were not assessed in this pilot study. The two aims of this study hence are:

1 To determine the relation between the satisfaction of the throathit given by an e-cigarette and the self-reported intent to switch from cigarettes to e-cigarettes.

2 To determine the OTH according to the combination of the voltage applied to the specific e-cigarette's resistance and the nicotine concentration of the e-liquid.

\section{METHODS}

\section{Participants}

A total of 35 students smokers participated in this blind experimental study (Supplementary Table1). The students were aged $22.0 \pm 7.7$ years; only two were 25 years old or older. Most (28/35) were males. Before the test, all participants are requested to fill in a short survey regarding their smoking habits, including the Heaviness of Smoking Index (HSI) scale and confirmed to be tobacco abstinent in the previous hour. Females confirmed that they were not pregnant and all participants were over 18 years old. Their expired CO was measured with a FIM Tabataba ${ }^{\circledR}$ CO tester (Lyon, France). All participants signed an informed consent form for the blind-test in the university facilities.

\section{Testing protocol}

Equipment

The 10 e-cigarettes used for each blind tests were the FUU ${ }^{\circledR}$ EGO type e-cigarette. The cartomizer contained an Aspire ${ }^{\circledR} 1.8 \mathrm{ohm}$ resistance. The $900 \mathrm{mAh}$ battery was fully charged at the beginning of each test. The voltage was set to either 3.5 or 4.5 volts at the beginning of the test (2 levels). Five e-liquid nicotine concentrations were tested (5 levels). The e-liquid was specifically prepared to have a nicotine level of $0,6,12,16$ and $18 \mathrm{mg} / \mathrm{ml}$ nicotine level. This range of nicotine concentration is representative of the liquids on the French market. The nicotine certified concentrations after gas chromatography-mass spectrometry (GC-MS) analysis on the final product were: $0.00 \mathrm{mg} / \mathrm{mL}, 6.06 \mathrm{mg} / \mathrm{mL}, 12.09 \mathrm{mg} / \mathrm{mL}, 16.05 \mathrm{mg} / \mathrm{mL}$, $18.09 \mathrm{mg} / \mathrm{mL}$. All e-liquids contained the same neutral flavour. The ratio of propylene glycol/glycerol was 75/25. There was an addition of water, alcohol or other additives in the tested e-liquids.

\section{Testing Session}

Each session was planned to include 10 smokers. Each smoker assessed 10 conditions of combination e-liquid/voltage apply to the resistance ( 2 voltage levels $\mathrm{x} 5$ nicotine concentration levels). A cross table was prepared to make sure that each condition was tested once by each of the 10 students. This table suppress the effect of training on the mean results of the 10 conditions tested in each session of the study. Each participant received a list from A to $\mathrm{J}$ in a randomized order corresponding to the 10 conditions to test from the cross table. Before each puff, the researcher verified that each student had the right e-cigarettes. The participants were blinded to the parameters and/or liquid used in each test.

\section{Production and Assessment of puff}

Each participant in each session took a 3 seconds puff (this duration is the median observed in the 1 million puffs study $)^{11}$ then exhaled and immediately self-assessed the puff.

The assessment of the puffincluded 2 parameters:

A) The throat-hit score concerning the subjective sensation recorded at time $t=5$ seconds (before the arrival of shoot of nicotine in the brain at second at 6-8 seconds). The baseline throat-hit with their usual cigarette was not assessed during this study but served as a reference for each volunteer to score the throat-hit in each of the experimental conditions. The throat-hit was scored from 0 to 9 ("In comparison to the throat-hit in the first 5 seconds of the puff of tobacco, how was the throat-hit of this e-cigarette"). The score 0 meant no satisfaction at all, the score of 9 meant full satisfaction of the throat-hit.

B) The "readiness to switch from tobacco to this e-cigarette product tested" were also scored, after each puff on a scale, from 0 (no chance to switch) to 10 (very high chance to switch).

The process was repeated every 5 minutes for a total of 10 puffs for each participant in a session.

\section{Statistical analysis}

Comparison of mean values was statistically evaluated by Student's t-test. The level of significance of $5 \%$ was selected. The coefficient of determination $\mathrm{r} 2$ was used to indicate how the regression line fits the data. The $\mathrm{XLSTAT}^{\circledR}$ statistical package was used for analyses.

\section{RESULTS}

\section{Baseline}

With regards to their smoking status, 21 of the smokers used full flavour cigarettes, one used a "light" cigarette, four used dark tobacco, six used roll your own cigarette, one used convertible tobacco; 2 students did not report the type of tobacco they smoked. The tobacco dependence assessed by HSI (from 0 to 6 ) revealed: a zero score 11 times, a score of 1-2 thirteen times, a score of 3-4 eight times, and a score of 5 one time. None had a 
maximum score of $6 / 6$. The mean measured expired $\mathrm{CO}$ varied from 9 ppm for smokers without tobacco dependence $(\mathrm{HSI}=0$ ) to $27 \mathrm{ppm}$ for smokers with high level of dependence (HSI=5). The majority of participants $(21 / 35)$ smoked their first cigarette in the first hour of the day.

\section{Tests}

The 35 smokers produced and assessed as planned 350 ecigarette puffs. The mean throat-hit score for all participants was $4.9 \pm 2.3$, with a mean individual score from 3 to 5.8 . The mean throat-hit score was $5.0 \pm 2.2$ for female and $4.8 \pm 2.4$ for male (non-significant). A mean throat-hit score of 5.12 .1 was observed for participants with a median HSI score (of 2-3), while participants with lower HSI score had a throat-hit score of $4.8 \pm$ 2.1 (non-significant) and those with higher HSI score had a mean score of throat-hit of $4.2 \pm 2.3$ (non-significant).

\section{Determination of optimal throat hit}

The mean throat-hit score increased during a learning process of 5 puffs. The throat-hit score increased by 0.3 points for each puff, for the 5 five puffs with a r $2=0.86$. After 5 puffs the mean throathit score reach a plateau (Figure 1). With the 3.5 volts setup, the optimal throat-hit score for each participant was obtained with a nicotine concentration between 0 to $18 \mathrm{mg} / \mathrm{L}$. In 7 volunteers with the 3.5 volts setup there was more than one OTH score value so the optimal concentration of nicotine associated with $\mathrm{OTH}$ could not be determined ( $20 \%$ of cases) With the 3.5 volts setup, the mean score of OTH was $6.88 \pm 1.65$. Nicotine concentration lower or higher than the concentration need for an OTH with a 3.5 volts setup was associated with a lower mean throat-hit score: the mean score for blind tests performed with a nicotine concentration lower than needed for the OTH was $3.72 \pm 1.39$ $(\mathrm{P}<0.01)$ and the mean score for tests with a nicotine concentration higher than needed to obtain an OTH was $2.92+$ $1.43(\mathrm{P}<0.01)$. With the 3.5 volts setup, the nicotine concentration associated with the OTH was reported three times to be $0 \mathrm{mg} / \mathrm{mL}$ and 11 times to be $18 \mathrm{mg} / \mathrm{mL}$

With the 4.5 volts setup, the OTH score for each participant was also obtained with nicotine concentrations from 0 to $18 \mathrm{mg}$ / L. In 4 volunteers with the 4.5 volts setup, there was more than one OTH score value so the optimal concentration of nicotine associated with OTH could not be determined for those cases (11.4\% of cases). With the 4.5 volts setup, the mean score for an OTH was $7.16 \pm 1.50$. As with the lower voltage setup, a nicotine concentration lower or higher than the concentration needed for an OTH was associated with a lower mean throat-hit score: the mean score for tests with a nicotine concentration lower than that of the OTH was 3.94 $\pm 1.63(\mathrm{P}<0.01)$ and the mean score for tests with a nicotine concentration higher than the OTH was $3.76 \pm$ $1.47(\mathrm{P}<0.01)$. With the 4.5 volts set-up, the nicotine concentration associated with the OTH was once $0 \mathrm{mg} / \mathrm{mL}$ and five times $18 \mathrm{mg} / \mathrm{mL}$ ( $14.3 \%$ of volunteers need $18 \mathrm{mg} / \mathrm{mL}$ of nicotine to reach the $\mathrm{OTH})$.

Tobacco dependence, as assessed by the HIS, was correlated with the concentration of nicotine in the e-liquid that provided the OTH. Each increase in 1 point on the HSI score was associated with a $1.6 \mathrm{mg} / \mathrm{mL}$ increase in the nicotine concentration of the e-liquid needed to obtain an OTH (Figure 2). The most frequent noted nicotine concentration that provided an OTH was $12 \mathrm{mg} / \mathrm{ML}$ with the 4.5 volts setup and $16 \mathrm{mg} / \mathrm{ML}$ nicotine with the 3.5 volts setup. The mean nicotine concentration to obtain an OTH was $12.6 \pm 9.0 \mathrm{mg} /$ for the 3.5 volts setup and $10.9 \pm 9.1 \mathrm{mg} / \mathrm{mL}$ for the 4.5 volts setup (nonsignificant) (Figure 3). A relationship was identified between the score of the "intention to switch from tobacco to e-cigarette" and the score of OTH $(\mathrm{r} 2=0.94)$ (Figure 4$)$. When the score of the selfreported intention to switch from tobacco to e-cigarettes was low $(0-3)$ the mean throat-hit score was also low (mean score $<1$ ). When the score of the self-reported intention to switch from tobacco to e-cigarettes was high (7-10), the throat-hit score was $>5$.

\section{DISCUSSION}

The assessment of a stable throat-hit was optimal after a teaching period of 5 puffs. The concentration of nicotine in the e-liquid that provided an OTH could be determined in more than $80 \%$ of cases. The assessment of the throat-hit in smokers who tested e-cigarettes is pertinent because the selfreported possibility to switch from tobacco to e-cigarettes with a specific nicotine concentration is linked to the throat-hit associated with this condition. The throat-hit increased until an optimal nicotine concentration, then decreased when the concentration was too high (except in some heavy smokers who experienced an OTH with the $18 \mathrm{mg} / \mathrm{L}$ nicotine concentration). The nicotine concentration need to obtain the OTH decreased when the electric power applied to the resistance increased. Moreover, there was a non-significant trend in this small pilot study that identified the need for a higher nicotine concentration in the e-liquid of smokers with high tobacco dependency as assessed by the HSI. Few retrospective studies have assessed the influence of the quality of the throat-hit on the switch from tobacco to e-cigarettes. Polosa $^{13}$ noted that the nicotine needed by e-cigarette beginners to obtain an adequate throat-hit was at medium or high nicotine concentrations in the e-liquid $(12-18 \mathrm{mg} / \mathrm{mL})$. After one year of e-cigarette use, a lower concentration of nicotine $(4-9 \mathrm{mg} / \mathrm{mL}$ ) was effective for most of the long term users. Moreover Etter ${ }^{14}$ conducted an internet based crosssectional 
Figure 1: Mean optimal throat-hit according to the rank in the series of 10 tests ( $n=35$ smokers by rank).

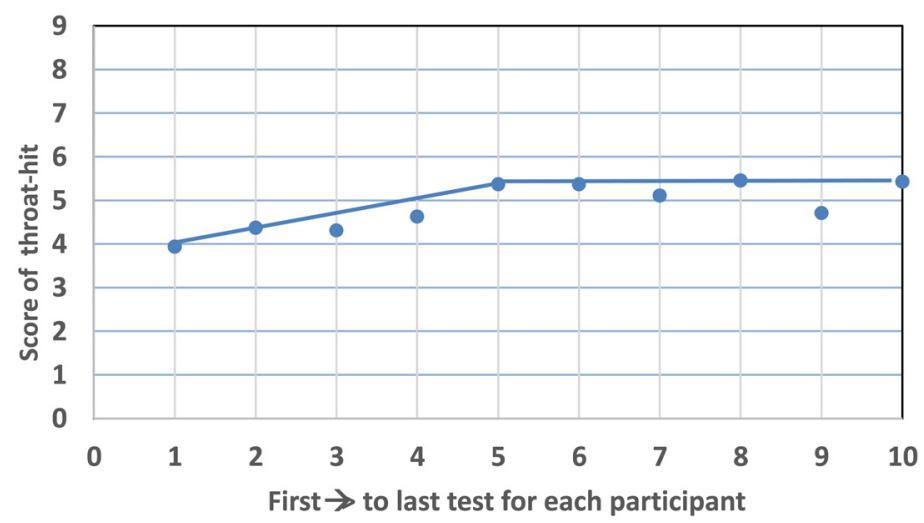

Figure 2: Nicotine concentration needed in the e liquid to obtain an optimal throat-hit (OTH) according to tobacco dependence as assessed by the IISI ( $n=3)$.

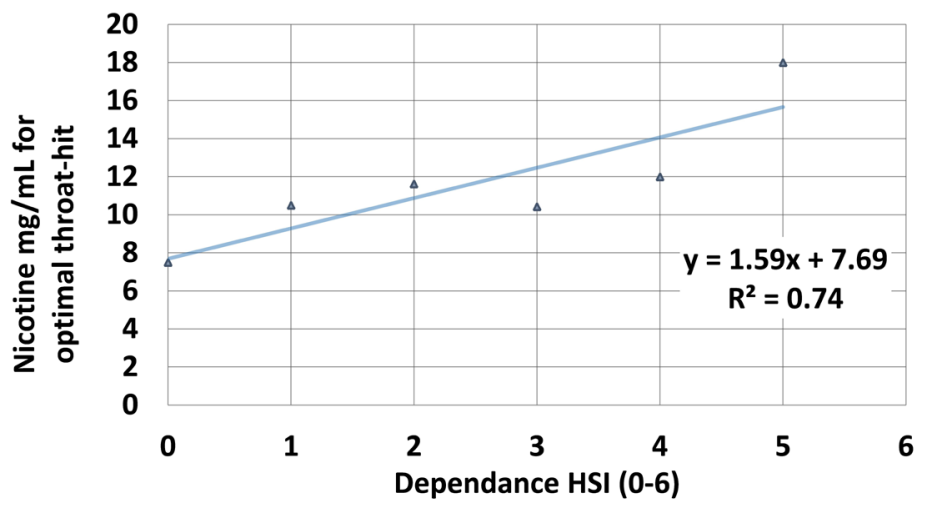

Figure 3: Mean nicotine concentration and voltage applied to the resistance to obtain an optimal throat hit (n=35 smokers).

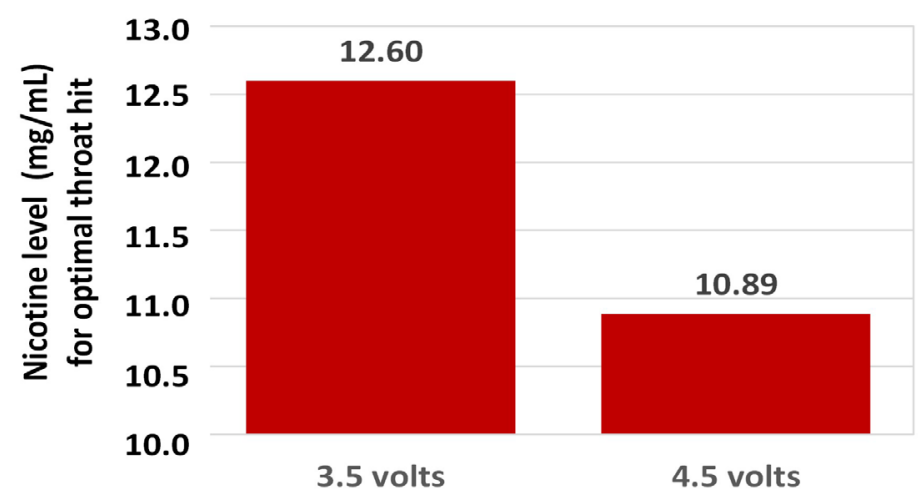

survey in 2012-2014 to assess the role of throat-hit. Among 1672 current users of e-cigarettes, the strength of the throat-hit was assessed. Those who reported a "very strong" throat-hit used liquids with a $17.3 \mathrm{mg} / \mathrm{mL}$ nicotine content, versus $7.1 \mathrm{mg} / \mathrm{mL}$ for those reporting a "very weak" hit $(\mathrm{p}<0.001)$. In this study, the strength of the throat-hit was linked with the perceived
Figure 4: Relationship between the mean throat-hit score and the score of the intent to switch from tobacco to e cigarettes (n=350 puffs).

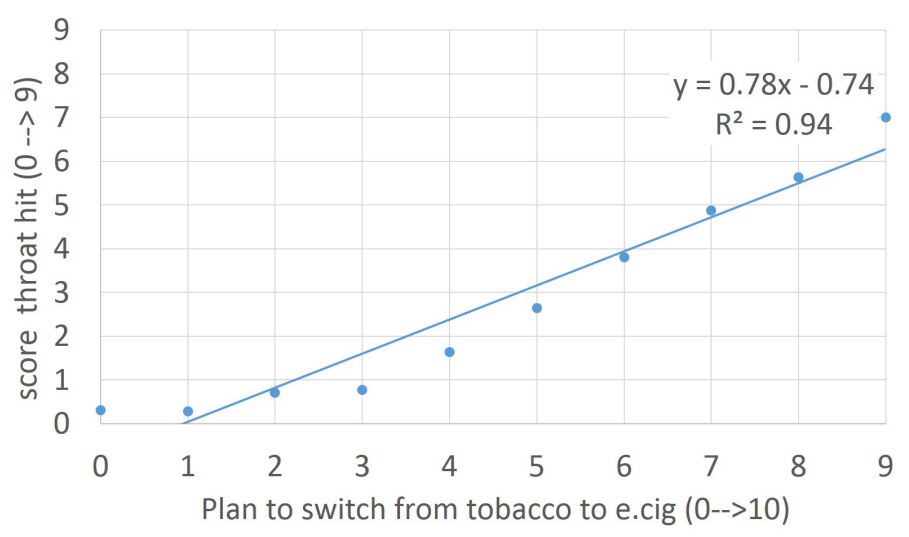

efficacy of e-cigarettes to relieve craving for tobacco and to facilitate smoking cessation. All the variables assessing satisfaction with e-cigarettes were associated with a better throat-hit.

\section{Study strengths and limitations}

The present study is prospective, specifically designed to assess the possible role of the throat-hit satisfaction in the intention to switch from tobacco to e-cigarettes. But this study, as all pilot studies, has limitations as it enrolled only students, mainly male and tested only one type of e-cigarette and one e-liquid flavour. However, this pilot study offers some evidence on the importance to assess throat-hit in the choice of e-liquid nicotine concentrations and the voltage to be applied to the resistance of the e-cigarette.

\section{CONCLUSIONS}

The present study has shown that the OTH and the corresponding nicotine concentration could be determined in $80 \%$ of cases with the low voltage setup ( 3.5 volt) and in $88.6 \%$ of case with high voltage setup ( 5.5 volt) under the experimental conditions of this study. The OTH needed the maximum nicotine concentration tested $(18 \mathrm{mg} / \mathrm{L})$ in $39.3 \%$ of cases with the lower voltage setup ( 3.5 volts), but only in $14.3 \%$ of cases with the higher voltage setup (4.5 volts). Hence, the $20 \mathrm{mg} / \mathrm{mL}$ limit of the EU Directive 2014/40/EU for nicotine concentration in eliquids seems to be pertinent as a maximum to protect users manipulating e-liquids and to provide enough nicotine concentration for the large majority of users.

When the throat-hit score is high, the desire to switch from tobacco to e-cigarettes is also high, so this throat satisfaction had to be taken in account by professionals to help smokers switch from tobacco to e-cigarettes. The relationship between OTH and the desire to use e-cigarettes, justifies improving e-cigarette technology and e-liquid to help smokers to quickly find the OTH. 
New studies are need to confirm the present results on other populations and to assess the role of e-liquid flavours and others additives, such as alcohol or water. The challenge for health professionals and regulators is to keep the e-cigarette attractive enough to invite smokers to switch from tobacco but in the same time leave the product non attractive to non-smokers.

\section{REFERENCES}

1. A- Trevizol AP, Cordeiro Q, Cook IA, Barros MD, Shiozawa P. Trigeminal Nerve Stimulation (TNS) for the Treatment of Irritable Bowel Syndrome in an Elderly Patient with Major Depressive Disorder: A Case Study. Brain Stimul. 2015,8:1235-6. doi: 10.1016/ j.brs.2015.09.001

2. Pritchard WS, obinson JH, Guy TD, Davis RA, Stiles MF. Assessing the sensory role of nicotine in cigarette smoking. Psychopharmacology (Berl). 1996,127:55-62. Erratum in: Psychopharmacology (Berl) 1996,128:432.

3. Strasser AA, Ashare RL, Kaufman M, Tang KZ, Mesaros AC, Blair IA. The effect of menthol on cigarette smoking behaviors, biomarkers and subjective responses. Cancer Epidemiol Biomarkers Prev. 2013,22:382-9. doi: 10.1158/1055-9965.EPI-12-1097.

4. Dawkins, L; Turner, J; Roberts, A; Soar, K "Vaping" profiles and preferences: An online survey of electronic cigarette users.

Addiction 2013,108:1115-25.

5. Farsalinos KE, Romagna G, Tsiapras D, Kyrzopoulos S, Spyrou A, Voudris V.Impact of flavour variability on electronic cigarette use experience: an internet survey. Int J Environ Res Public Health. 2013,17:7272-82. doi:10.3390/ijerph10127272.

6. Walker N, Howe C, Bullen C, Grigg M, Glover M, McRobbie H, Laugesen M, Jiang J, Chen MH, Whittaker R, Rodgers A. Does improved access and greater choice of nicotine replacement therapy affect smoking cessation success? Findings from a randomized controlled trial. Addiction. 2011,106:1176-85. doi:10.1111/j.13600443.2011.03419.x.

7. Lechner WV, Tackett AP, Grant DM, Tahirkheli NN, Driskill LM, Wagener TL. Effects of duration of electronic cigarette use. Nicotine Tob Res. 2015,17:180-5. doi: 10.1093/ntr/ntu061.

8. Dawkins L, Corcoran O. Acute electronic cigarette use: nicotine delivery and subjective effects in regular users. Psychopharmacology 2014,231.2: 401-7.

9. Schneider, NG, Olmstead, RE, Nides, M, Mody, FV, Otte-Colquette, $\mathrm{P}$, Doan, K, et al. Comparative testing of 5 nicotine systems: Initial use and preferences. American Journal of Health Behavior 2004,28:72-86.

10. Steinberg MB, Zimmermann MH, Delnevo CD, Lewis MJ, Shukla P, Coups EJ, Foulds J. E-cigarette versus nicotine inhaler: comparing the perceptions and experiences of inhaled nicotine devices. J Gen Intern Med. 2014,29:1444-50. doi: 10.1007/s11606-014-2889-7.

11. Schneider, NG, Terrace, S, Koury, MA, Patel, S, Vaghaiwalla, B, Pendergrass, R, et al. Comparison of three nicotine treatments: Initial reactions and preferences with guided use. Psychopharmacology 2005,182:545-50.

12. Dautzenberg B, Bricard D. Real-Time Characterization of ECigarettes Use: The 1 Million Puffs Study. J Addict Res Ther 2015,6:229. doi: 10.4172/2155-6105.1000229

13. Polosa R, Caponnetto P, Cibella F, Le-Houezec J. Quit and smoking reduction rates in vape shop consumers: a prospective 12 -month survey. Int J Environ Res Public Health. 2015,12:3428-38. doi: 10.3390/ijerph120403428.

14. Etter JF Throat hit in users of the electronic cigarette: An exploratory study. Psychol Addict Behav. 2016,30:93-100. doi: 10.1037/adb0000137.
CONFLICT OF INTEREST The authors have completed and submitted the ICMJE Form for Disclosure of Potential Conflicts of Interest and one of the authors (AS) founded an e-cigarette company independent of the tobacco industry (Enovap $($ ). All other authors remain free of any conflicts of interest for this article.

FUNDING

There was no source of funding for this research.

PROVENANCE AND PEER REVIEW

Not commissioned: externally peer reviewed 